\title{
ERRATA
}

\section{Genetic Testing Before Anticoagulation? A Systematic Review of Pharmacogenetic Dosing of Warfarin}

\author{
Kirsten Neudoerffer Kangelaris, $M D^{1,2}$, Stephen Bent, MD ${ }^{1,4}$, Robert L. Nussbaum, $M D^{3}$, \\ David A. Garcia, $M D^{5}$, and Jeffrey A. Tice, $M D^{7}$ \\ 'Division of General Internal Medicine, University of California, San Francisco, CA, USA; ${ }^{2}$ Division of Hospital Medicine, University of California, \\ San Francisco, CA, USA; ${ }^{3}$ Division of Medical Genetics, University of California, San Francisco, CA, USA; ${ }^{4}$ Division of General Internal Medicine, \\ Veterans Affairs Medical Center, San Francisco, CA, USA; ${ }^{5}$ Department of Medicine, University of New Mexico, Albuquerque, NM, USA.
}

(c) Society of General Internal Medicine 2009

T $\mathrm{n}$ the Review, "Genetic Testing Before Anticoagulation? A Systematic Review of Pharmacogenetic Dosing of Warfarin" by Kirsten Neudoerffer Kangelaris, Steve Bent, Robert L. Nussbaum, David A. Garcia and Jeffrey A. Tice (JGIM. 2009 May: 24(5):656-64), we made a typographical error in units of hemoglobin specified for the definition of major bleeding. We stated that "a fall in hemoglobin greater than or equal to $2 \mathrm{mg} / \mathrm{dL}$ " was one criterion for major bleed. The correct definition is greater than or equal to $2 \mathrm{~g} / \mathrm{dL}$. This error did not effect our results or conclusions.

Corresponding Author: Kirsten Kangelaris, MD; University of California, San Francisco, Department of Internal Medicine, 533 Parnassus Ave, Box 0131, San Francisco, CA 94143-0131 (e-mail: kkangelaris@medicine.ucsf.edu).

The online version of the original article can be found at http://dx.doi. org/10.1007/s11606-009-0949-1

Published online September 16, 2009 